This is an authors accepted manuscript for a chapter in the book Teaching With Sociological Imagination in Higher and Further Education Contexts, Pedagogies, Reflections edited by Christopher R. Matthews Ursula Edgington Alex Channon, available here - https://link.springer.com/book/10.1007/978-981-10-6725-9

\title{
Doing Public Sociology in the Classroom
}

Dr Christopher R. Matthews,

School of Science and Technology, Nottingham Trent University

Email: Christopher.Matthews@ntu.ac.uk 


\title{
Doing Public Sociology in the Classroom \\ Christopher R. Matthews (Nottingham Trent University)
}

\begin{abstract}
Within this chapter I explore the manner in which public sociology (Burawoy, 2004) might be usefully employed to enhance teaching and learning. After arguing for an orientation to teaching that centralises students' experiences by 'starting from where they are' I outline three practical stages in the doing of public sociology in the classroom. These overlapping stages are important as a means of supporting the development of foundational skills that enable more challenging work towards the end of undergraduate study. In conclusion, I suggest that by integrating elements of public sociology across a curriculum colleagues can enhance their degree programme in terms of employability, engagement and student satisfaction. I also suggest that this process offers some key avenues for tackling some of the pressures and challenges that sociology faces as a discipline.
\end{abstract}

\section{Introduction}

When I conducted my Ph.D. there was very little pressure placed on me to engage in any sort of public engagement. While I reported my findings at a number of conferences and within academic publications, I did not attempt to write about my work in a manner that would be accessible to non-academics, nor did I make policy recommendations or feed my results back to any governing bodies or government agencies. Perhaps this was a product of the expectation that I, as with the majority of those who hold an advanced degree in sociology, would go on to work in the 'ivory towers' of academia rather than the 'real' world? Perhaps this was a manifestation of the lack of sociologists' voices in shaping debates around public policy? Whatever the reason, this has left me with a personal motivation to develop a thread of activism connected to my research and to develop my ability to meaningfully contribute to public issues ${ }^{1}$.

Thinking and working through this process in relation to my own work has highlighted to me the important potential that public sociology has for our students in terms of skill

\footnotetext{
1 This is most clearly demonstrated in my work with Alex Channon on the Love Fight Hate Violence project - LFHV.org and within my development of LGBTQI boxing spaces.
} 
development, employability and creating interesting learning and teaching opportunities. And as higher education becomes an increasingly competitive and marketised space I argue that in feeding public sociology into our learning and teaching sociologists can mark out and lay claim to the development of students' employability in a more explicit manner.

In this chapter I reflect on some of my thoughts around this topic and provide some practical examples and suggestions that might be useful for those wishing to use such ideas in their teaching, learning and curriculum development. To do this I offer insight into how lecturer/learner relationships can be recast to provide a more practical and engaged education. In conclusion, I make a call for colleagues to tackle some of the pressures and challenges that sociology faces as a discipline by considering the examples I present when conducting curriculum reviews and development. To provide some context let me briefly discuss public sociology and how we might want to consider it in relation to our teaching.

\section{Genuinely Student-Centred Public Sociology}

Public sociology, as proposed by Burawoy (2004), has provided a contemporary focal point for academics wishing to engage in what might previously have been understood as activism, public debate, policy creation, action-orientated research and collaborative research. Burawoy $(2004,104)$ argues that we need to bring sociology to people and groups beyond academia in order to promote "dialogue about issues that affect the fate of society, placing the values to which we adhere under a microscope". He continues:

What is important here is the multiplicity of public sociologies, reflecting the multiplicity of publics - visible and invisible, thick and thin, active and passive, local, national and even global, dominant and counter publics. The variety of publics stretches from our students to the readers of our books, from newspaper columns to interviews, from audiences in local civic groups such as churches or neighbourhoods, to social movements we facilitate. The possibilities are endless. (Burawoy, 2004, 104)

This call to action has been met by many sociologists conducting research in a variety of fields and has aided the process of re-establishing our discipline as a central voice in public debates (see Nyden, Hossfeld and Nyden (2012) for a collection of examples).

Alongside this impetus in research a number of institutions in Europe (Humboldt State University, Nottingham Trent University, Queen Margaret University) and America (American University Washington, Baker University, University of the Rockies, University of North Carolina Wilmington) now offer degree programmes in public 
sociology. And at a personal level, while organising and speaking at a number of British Sociological Association Teaching Group regional conferences, I have had interesting discussions with many colleagues who have weaved elements of public sociology into their teaching and learning. It appears, whether explicitly or not, that Burawoy's (2004) comments have formed the basis from which some colleagues are developing interesting and well-recruiting degree programmes.

Yet, it is important to think through what we mean when we talk about public sociology and, specifically when considering teaching, whose public sociology we are doing in the classroom. Burawoy (2004) points to students as the most readily available public for whom scholars have access. Indeed, Persell (2009) argues that teaching may be the most commonly practiced form of public sociology. A shallow reading of these ideas can result in academics considering students as the recipients of public sociology rather than as a group with whom one might do public sociology. The former orientation might align well with the self-focus that is often required and developed in successful Ph.D. researchers and many academics. However, it is also at odds with what many students require from their degree programmes. Furthermore, it stunts the potential that understanding students as active participants in sociology can have for generating powerful learning experiences.

Burawoy (2004, 9, emphasis added) provides a useful point of departure for developing such considerations when he envisaged teaching and public sociology in a nuanced and genuinely student (public) centred manner:

With the aid of our grand traditions of sociology, we turn their private troubles into public issues. We do this by engaging their lives not suspending them; starting from where they are, not from where we are. Education becomes a series of dialogues on the terrain of sociology that we foster - a dialogue between ourselves and students, between students and their own experiences, among students themselves, and finally a dialogue of students with publics beyond the university.

The key for Burawoy appears to be a shift in the ways that higher education has traditionally been framed. As academics are largely employed for their specialist knowledge on specific topics we often feel very passionate about our areas of research. This personal investment can provide a great starting point from which we can develop engaging and interesting lectures and assessment strategies. We also tend to feel more comfortable lecturing on the ideas that we hold closest to us. Indeed, our students commonly expect, and even demand, that we are experts in a myriad of topics (in a later section of this chapter I discuss how such expectations might be managed). 
When these issues are combined with the power dynamics that often frame social interactions in the classroom, such as those between lecturer/learner, expert/novice, senior/junior, we can begin to see a tension between traditional academic lecturing and the dialogical teaching that Burawoy envisaged. And the result is that the vast majority of higher education still 'starts from where we are'. But in 'starting from where they are' it is possible to deconstruct and recast the process of teaching and learning in a manner that is weighted more favourably towards student's lives, interests and the skills they need in order to develop their critical thinking, career pathways and ultimately their ability to gain employment.

In 'starting from where they are' it is possible to begin to work with their emotional connections to certain social worlds and phenomena. Rebekah Widdowfield (2000) and Kye Askins (2009) have explored this in relation to situating the emotions in research. I find such ideas useful as a means of helping students examine issues that they care about. Indeed, during the collection of module feedback, students have told me that some of their most powerful learning experiences came as a result of feeling empowered to critically explore topics that they are emotionally invested in.

Connecting in this manner to students' emotional lives is an important way that we can produce an interesting 'hook' for our academic arguments and discussions of more abstract theoretical ideas. And while it would be overly simplistic to consider this as a process of developing their public sociology rather than ours, working towards such a shift does help to undermine the unequal power dynamic of traditional, university-style education. This is not a new pedagogical idea and many readers will report the success they have had using variations upon such a theme; yet, in re-articulating this focus using public sociology Burawoy provides an important point of departure for scholars who are interested in developing a range of powerful and practical learning opportunities.

A further way of conceptualising this process was neatly captured by my co-editor and colleague, Alex Channon, who, while we were considering the teaching and learning for a new module, argued for the development of 'a sociology for' rather than 'a sociology $o f$. Here, rather than focusing on sociology as a means of understanding a given topic the focus shifts to a sociology that is useful for people (publics) who have an interest or work in a particular setting, vocation or career. A sociology for would provide practical toolkits for understanding, doing and effecting change based on a sociological understanding. 
It is then possible to provide more explicit opportunities for our students to develop sociological knowledge and tools that have a practical resonance with their lives and potential future careers. There is a neat link here between Burawoy's discussion of the need for a dialogue with our students about the terrain for public sociology and a commitment to developing our students' practical usage of the sociological imagination. Here we have a practical public sociology developed for usage in areas and environments that our students care about and feel are important, interesting and useful for their careers. And I argue that aligning in this way with the increasingly important 'employability agenda' sociologists will have more tools available to them in terms of degree recruitment and student retention.

\section{The Process of Doing Public Sociology in the Classroom}

The preceding thoughts act as a broad framework that has shaped my teaching and curriculum development in line with some central ideas drawn from public sociology and my personal pedagogical approach. Building on this, the following practical examples aim to provide colleagues with clear examples to stimulate their own usage of public sociology in the classroom. These examples are based on my implementation of such ideas on a degree programme that I lead at the University of Brighton. This is not a sociology degree, and while social scientific thinking takes a central place within the academic study, it is important to draw attention to this context as it highlights the potential embedded in deploying public sociology outside of the sociology departments and programmes.

Importantly, my leadership role has afforded me the space to develop the degree across all three years of study, thereby contextualising and structuring learning for students over time. This provides a coherence and logical progression that is essential for all teaching, but especially so when attempting to develop the critical thinking skills and knowledge that is useful for doing public sociology. As such, I will outline three broad and overlapping stages that encourage students to gradually and progressively develop their abilities. These ideas can map neatly onto the first, second and third years of study during an undergraduate programme; however, readers might want to reconsider this ordering to suit their own students' characteristics and needs.

\section{Personalising the Sociological Imagination as the Basis for Public Sociology}

As with all educational processes it is important to begin working with our students at the appropriate level. There are many elements of sociology that undergraduate students struggle to grasp due to lack of prior learning, lack of life experiences or the 
novelty and/or complexity of theoretical ideas. As such, initial steps down the pathway towards public sociology should be taken slowly and with lots of direction. A good start point for this is to focus on developing students' abilities to use sociological concepts and ideas to help understand elements of their own lives. Again, this is not a new idea within teaching and learning, but it is important to discuss this initial stage as it can encourage our students to begin to see the practical potential embedded in the sociological imagination.

When I meet students in the first semester of their undergraduate programme I encourage them to personalise the ideas I present to them. I discuss this as part of an informal teacher/learner contract where I set out what they can expect from me and what I expect from them. Following this I regularly weave personal stories into my lecturing on foundational sociological ideas. A favourite I use at the moment is connected to ideas around the 'quantified self'. For this topic I show them a display from my Strava account (a social media technology that is used to track one's running and cycling). Unpicking my modest yet incrementally improving performances opens up issues around disciplining bodies, big data and the rationalisation of (what should be enjoyable) physical activity, in a potentially amusing manner. Most students are able to relate this example to their own lives and, as such, this begins the process of them seeing the sociological imagination as something that has a practical utility.

Building on such examples, I set tasks were they have to relate ideas from lectures and readings to their interests, pastimes and personal experiences. The key here is to provide them with opportunities to bring themselves into their studies. The following is an example of a group task I set in the first few weeks of starting their undergraduate studies:

Based on your assigned reading of the extract from C. Wright Mills, work in small groups to develop a presentation about 1) a public issue which can be understood using sociological ideas and 2) provide anecdotal evidence from personal problems to help bring your presentation 'to life'.

The students develop this task during the course of three seminars; this enables them to work together under my supervision to find accessible sociological research that speaks to some of their personal experiences. The presentation of this work back to the class offers further pedagogical opportunities as the students learn from each other's attempts to personalise sociology. In carving out this sort of space for students to explore sociology on their terrain we can begin to develop the dialogical teaching that Burawoy highlighted. 
When asking students to draw on their personal (potentially emotional) experiences and problems it is not uncommon for challenging and powerful stories to be discussed. I am not one to shy away from the appropriate use of such ideas within teaching and learning but certain safeguards must be considered (see Lowe in this book for further discussions around this topic). It is essential, then, that the classroom in which such tasks are being developed is a safe and respectful space. This is especially the case when working with first year students who have come from a variety of different educational settings with different social norms and behavioural standards.

Once such a safe space has been created our students will feel far more comfortable discussing their own lives and relating these experiences to important sociological ideas. This can also be accompanied by discussions around the nature of subjective experiences and differences in biography to help develop empathic thought processes that will be useful for working with different publics. When done in a sensitive manner, such personalised learning experiences can provide a great foundation for our students' attempts to work with and for different publics.

\section{Producing Ideas for Different Publics}

We spend a lot of time developing our students' abilities to discuss ideas in an 'academic style'. And while there is much debate around what constitutes such a style, the process of learning the skills associated with academia are one of the hallmarks of higher education. While key skills are developed when developing such an approach, many of our students will seldom draw on their abilities to write, present and produce ideas using academic language in their chosen careers. Moreover, it is surely conceivable to imagine a process whereby the ability to produce ideas for non-academic audiences might suffer as our students spend so much time and effort crafting the skills we academics find to be important.

Some will undoubtedly disagree with my position here, but what is clear to me is the importance that should be placed on encouraging our students to develop the ability to express intellectual ideas in an accessible and efficient manner for various publics outside of academia. This is also clearly an important dimension of developing skills that align neatly with an essential dimension of public sociology. This synergy is the basis from which I have worked with students to help them produce ideas for different publics. 
There are two key elements that I consider to be central in organising strategies that help students work with these ideas. Firstly, it is important to consider the appropriate medium for presenting different ideas to different publics. For example, how might we best spread ideas about health inequality to diverse populations? Or how could we effectively promote positive body images in a digital age? Thinking through the practicalities of how, and in what ways, we translate academic research and concepts is an interesting pedagogical exercise and requires students to engage in a process of empathising with different subjective positions.

Secondly, it is important that there is an internal consistency between such considerations and the manner in which our students deliver their work. Spending time developing the ability to align the medium and content of ideas provides further pedagogical exercises, interesting dimensions to assessments and, perhaps most importantly, is a skill that can be of use in a variety of careers and workplaces.

For students to develop the internal consistency between the idea and the media of representation it is essential that we provide interesting and thought-provoking examples. In this sense, social media has been argued to be an effective teaching and writing tool (see Edgington \& Wilton, this edition) and I have used the Twitter hashtag \#EverydaySexism, which has been developed by the Everyday Sexism campaign (see Bates, 2016), as a hook to help students get into such ideas:

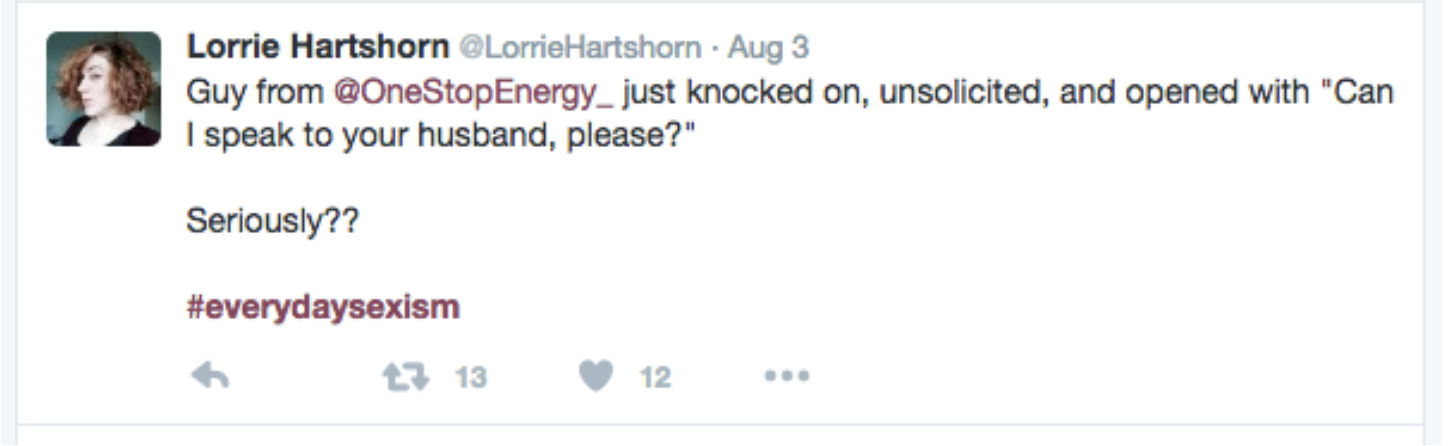

The \#Everydaysexism campaign effectively highlights the often taken for granted, unthinking and embodied nature of unequal gender relations. It is a great example of feminist social theory being translated into an easily understood and quickly distributed idea. Building on this example, students can be asked to work in groups to research and deconstruct a variety of other such examples. Here, students are able to being to develop the skills needed to distilling key information and presenting it with simplicity and clarity with the specific needs of different publics in mind. 
I prefer to produce student engagement through interesting teaching and empowering students, yet, it is also important to accept that many students will attempt to work strategically towards specific learning outcomes. As such, weaving this style of teaching throughout a module and ensuring it is a central element of the assessment can ensure 'buy in' from those more strategically-minded learners. The following is an extract from an assessment brief that I have used in the past:

Task One - Take one or more of the themes we have discussed in this module and reproduce them for a non-academic audience of your choosing. Your work could take the form of a blog, activism campaign, artistic representation, poster, journalistic or fiction writing, satirical or comic representation and other appropriate styles. We will explore examples of such work within the module and you will be expected to discuss your idea with a module tutor at least three weeks before the assessment is due.

Task Two - Write a discussion about the theme(s) you have chosen to reproduce. You will be expected to outline the academic basis for your work by including references to relevant literature. Building on this you should outline a coherent logic that explains and justifies the medium and delivery of your ideas. Why have you chosen to do what you have done in the way that you have done it? Why does this fit with the population you have chosen to target?

Such tasks can require a lot of effort from students who are used to more prescriptive and less practically minded assessments. In order to support students I provide lots of opportunities for them to develop their ideas during seminars and workshops. Here we discuss ways in which lecturing material might be effectively communicated to different groups. Providing realistic scenarios for students to work through is very useful; for example, asking them how they might go about highlighting gentrification to local residents, or workplace inequality to their colleagues at work. Taking such concrete examples and working them through to a conclusion in a group workshop can really aid students' abilities to present ideas in a manner which can often be outside of the knowledge base and comfort zone of academics. And it is here, by working from 'where they are' and where different publics might be, that we can enhance and unleash our students' powers to creatively work with and for different publics and to move beyond some of the inertia that can sometimes accompany dry academic debates.

\section{Doing Sociology with Publics Beyond the University}

There is a general expectation that our final year students are able to handle more complex theoretical and conceptual ideas. While this if often the case, and I have been impressed by how many of my students have grasped some of the finer points of social theory, I often reflect on the manner in which such knowledge will be of direct use for them in their chosen careers. Yes, these ideas can be useful for their own personal 
development in terms of reading social situations, and sharpening critical thinking, but in terms of direct application in the workplace and for developing their own employability it can often be challenging for students to see the practical dimensions that can accompany such knowledge. Yet, it is possible to help our students to realise and develop the potential for such sociological ideas by weaving into our teaching and assessments a commitment to working with publics beyond the University. This can provide clear practical examples for our students to draw upon when applying for jobs and helps them demonstrate that they can pragmatically deploy their academic knowledge.

In this final stage of doing public sociology in the classroom our students are putting their skills into practice. As many students will be working in this practical way for the first time it is important that enough space is given over to them to explore examples of such work and to create their own ideas. As such, when working in this way I usually divide the hours I spend with them equally between lecturing about new empirical and theoretical content, seminars which focus on critical evaluations of interventions, and workshops, tutorials and discussion groups where students are able to develop their own ideas. This shift deemphasises lecturing as the central feature of a module and refocuses the lecturer's role to produce and support a dialogue between key academic themes, students' interests and practical outcomes.

When splitting teaching time in such a manner it is important to firstly manage our own expectations about how much academic content can be covered. Developing teaching and learning in the manner I am describing places different pressures and expectations on students and requires a shift in the types of support we provide. In carving out working and thinking time for this process it is essential to pare back either the depth or volume of ideas that would normally be covered when teaching is orientated around the traditional lecture/reading format. It can be challenging at first to 'let go' of themes and lectures that we as scholars find important, but it is essential to remember that this process is about supporting our students' development in directions that are useful and important to them, rather than being solely dictated by us.

A second potential issue comes in the form of managing students' expectations of the teaching process. I have found that when reducing the amount of 'chalk and talk' some students find the increased need for them to become actively engaged in their own learning to be challenging. This breakdown of the traditional 'I talk, you listen' dynamic can be disconcerting for some. I have found that such issues can be managed by 
outlining the positive reasons for this style of teaching, highlighting the differences in what the students can expect from you and in return what you expect from them, drawing attention to employability opportunities that are embedded in this process, and finally, by offering extra support and guidance for students who are less comfortable learning in such a fashion. When this is done the vast majority of students in the final year of their studies are able to see the importance of recasting the learning process in this manner as a means of supporting their development of key skills and increasing their ability to gain employment.

When working in this way with students at the University of Brighton I have used our Community and University Partnership Programme (CUPP) as a means of setting a practical scenario for assessments. CUPP keeps a record of all the projects it helps to set up; this information highlights how university staff have been working with community partners to develop social justice campaigns, small businesses, funding bids and a variety of other activities. This gives my students a great chance to see practical examples of academic knowledge being used in real world situations. As such, I am able to use the CUPP application forms and supporting documents in the following assessment:

You have been approached by an organisation that is seeking an academic partner to support their development of a programme that will tackle a pressing social issue. Together you have decided to apply for CUPP funding.

Task One - Complete a short review of literature around the key academic themes that underpin your project. This work should clearly highlight the social issue that you and your community partner are interested in.

Task Two - Building on your literature review develop a CUPP funding bid that is designed to help you and your partner develop a project around the theme you are interested in. Your bid should be completed using the current CUPP application form and provide the required supporting documents.

This assessment ensures that students can work on an area that they have some interest in. It also encourages them to consider the issues within this topic in line with the needs and motivations of a specific group. And finally, by developing a funding bid for a project based on academic literature they are pulling together skills in a manner that is extremely valuable and applicable to life beyond the campus.

\section{Concluding Remarks}

The preceding examples of how I have developed some elements of public sociology in the classroom are meant to offer the reader some insights into how they could add such 
ideas into their teaching, learning and curriculum development. In this regard I align with Nyden, Hossfeld and Nyden $(2012,300)$ who conclude that:

Preparing sociologists for engaged scholarship means rethinking the academic programs we currently offer to ensure graduates have the skill set needed to work outside academia, creating a curriculum that reflects the growing needs of the $21^{\text {st }}$ century sociologist.

There are many imaginative and interesting ways that this could be done and I encourage colleagues to play around with some of these ideas while conducting curriculum reviews. I have presented the above examples as overlapping progressions because I consider such stages to be essential for students to confidently work in this publically engaged and practical manner. Without providing opportunities to think about personalising sociology and then empathising with different publics I have found from experience that students often do not have an orientation to learning and assessments that aids them in doing public sociology. And while colleagues should not be put off from including elements of public sociology in stand alone modules, I certainly believe that a strategic and well thought out deployment of such ideas across all levels of an undergraduate programme can lead to a more positive learning experience.

In reconsidering teaching and learning in this style sociologists can have a clear impact on our student's critical thinking skills and, as I have argued in this chapter, employability. This also provides a clear narrative during open days to help highlight to prospective students and their parents/guardians the different career opportunities that an undergraduate education in sociology can offer. I would argue that public sociology provides a useful fulcrum around which sociology as a discipline can meet some of the demands that changes to the structure of higher education are bringing. And while we must be critical of the marketisation of education and the undermining effects of neo-liberal agendas, as a discipline we must also not get caught on the sideline as other subjects continue to lay claim to and leverage the employability agenda.

As I have tried to show here, with some small changes in focus, aligned to public sociology, it is possible to develop teaching, learning and assessments that specifically work towards the use of the sociological imagination in real world settings. In supporting our students' in this manner we are not only developing their potential employability, we are also working towards maximising our discipline's potential to act as a foundational academic basis for public debate, public policy and community development. 
I argue that degree programmes that draws on some of these themes and ideas will be well placed to offer learning experiences that are engaging, challenging and enjoyable, while also encouraging the development of crucial practical skills that are essential for enhancing employability. It is easy to dismiss the need for such changes as the negative results of shifts in the educational system towards neo-liberal agendas. But as I have previously argued (Matthews, 2014), the 'brave new world' of academia, while filled with problems and issues, might also provide an impetus to bring students' experiences and needs more fully to the centre of teaching and learning. For me, this is something that sociology as a discipline should be leading the way on, and I suggest the preceding ideas and examples as a basis from which colleagues might want to consider this in their own degree programmes.

\section{Suggested Discussion Points}

1. What sociological themes shape the lives of your students most acutely, how could these be used to engage them?

2. What local organisations or groups could you work with to help your students consider the utility of the sociological imagination outside of the classroom?

3. How can you help your students conduct assessment work that will have clear and practical resonance with life outside of academia?

4. What examples from work within your department/colleagues could you use to illustrate the potential for public sociology? 


\section{References}

Askins, K. (2009) 'That's Just What I do': Placing Emotion in Academic Activism. Emotion, Space and Society, 2, 4-13.

Burawoy, M. 2004. “For Public Sociology” American Sociological Review 70(1): 4-28.

Nyden, P.W., Hossfeld, L.H. and Nyden G. (2012) Public Sociology: Research Action and Change. London, Sage.

Matthews, C.R. (2014) Teaching Reforms, Not All Bad. Network Magazine of the British Sociological Association, 119, 44-45.

Persell, C.H. (2009) Teaching and Public Sociology. In V. Jefferies (Ed.) Handbook of Public Sociology. Maryland, Rowman and Littlefield Publishers.

Widdowfield, R. (2000) The Place of Emotions in Academic Research. Area, 32(2), 199208.

Bates, L. (2016) Everyday Sexism. Thomas Dunne Books, New York, NY. 
